\title{
Mass Spectrometry for Proteomics
}

\author{
Xuemei Han ${ }^{\dagger}$, Aaron Aslanian ${ }^{\dagger} \ddagger$, and John R. Yates III $^{\star}, \dagger$ \\ $\dagger$ Department of Chemical Physiology, The Scripps Research Institute, 10550 North Torrey Pines Road, La \\ Jolla, CA 92037 \\ $\$$ Molecular and Cell Biology Laboratory, The Salk Institute for Biological Studies, 10010 North Torrey, Pines \\ Road, La Jolla, CA 92037
}

\section{Summary}

\begin{abstract}
Mass spectrometry has been widely used to analyze biological samples and has evolved into an indispensable tool for proteomics research. Our desire to understand the proteome has led to new technologies that push the boundary of mass spectrometry capabilities, which in return has allowed mass spectrometry to address an ever-increasing array of biological questions. The recent development of a novel mass spectrometer (Orbitrap) and new dissociation methods such as electron transfer dissociation have made possible exciting new areas of proteomic application. Although bottom-up proteomics (analysis of proteolytic peptide mixtures) remains the workhorse for proteomic analysis, middle- and top-down strategies (analysis of longer peptides and intact proteins, respectively) should allow more complete characterization of protein isoforms and post-translational modifications. Finally, stable isotope labeling strategies have transformed mass spectrometry from merely descriptive to a tool for measuring dynamic changes in protein expression, interaction and modification.
\end{abstract}

\section{Introduction}

The complete characterization of all proteins has been the goal of proteomics since its inception almost 25 years ago. The features by which a protein can be described are many; these include but are not limited to expression, localization, interaction, domain structure, modification and activity. If the proteome of an organism is considered to be all protein forms expressed, including splice isoforms and post-translational modifications (PTMs), this represents a considerably complex body of information to gather. Whereas the genome of an organism generally does not vary from cell to cell, such is not the case for the proteome. Even for a single cell, the proteome will change in response to different stimuli. Traditional techniques have focused on understanding the function of individual proteins. Coinciding with the availability of completed genome sequences, there has been a shift to more comprehensive proteome analyses.

Amongst the toolkit of techniques with which proteins can be investigated on a large scale, mass spectrometry (MS) has gained popularity because of its ability to handle the complexities associated with the proteome. Other techniques such as two-dimensional gel electrophoresis (2DE), two-hybrid analysis, and protein microarrays fail to achieve the depth of informative proteome analysis seen with mass spectrometry. The three primary applications of MS to

\footnotetext{
*Corresponding author. E-mail jyates@scripps.edu.

Publisher's Disclaimer: This is a PDF file of an unedited manuscript that has been accepted for publication. As a service to our customers we are providing this early version of the manuscript. The manuscript will undergo copyediting, typesetting, and review of the resulting proof before it is published in its final citable form. Please note that during the production process errors may be discovered which could affect the content, and all legal disclaimers that apply to the journal pertain.
} 
proteomics are cataloging protein expression, defining protein interactions, and identifying sites of protein modification. The use of MS for proteomics is not the application of a single technique for all purposes but rather a collection of methodologies, each with strengths suited to particular inquiries. For any MS experiment, consideration should be given to the type of instrumentation, fragmentation method and analysis strategy best suited to an individual sample. This review will focus on these topics with emphasis on new developments and their recent applications.

\section{Mass spectrometric instrumentation for proteomics}

Fundamentally, MS measures the mass-to-charge ratio $(\mathrm{m} / \mathrm{z})$ of gas-phase ions. Mass spectrometers consist of an ion source that converts analyte molecules into gas-phase ions, a mass analyzer that separates ionized analytes based on $\mathrm{m} / \mathrm{z}$ ratio, and a detector that records the number of ions at each $\mathrm{m} / \mathrm{z}$ value. The development of electrospray ionization (ESI) [1] and matrix-assisted laser desorption/ionization (MALDI) [2], the two soft ionization techniques capable of ionizing peptides or proteins, revolutionized protein analysis using MS. The mass analyzer is central to MS technology. For proteomics research, four types of mass analyzers are commonly used: quadrupole $(\mathrm{Q})$, ion trap (quadrupole ion trap, QIT; linear ion trap, LIT or LTQ), time-of-flight (TOF) mass analyzer, and Fourier-transform ion cyclotron resonance (FTICR) mass analyzer. They vary in their physical principles and analytical performance. "Hybrid" instruments have been designed to combine the capabilities of different mass analyzers and include the Q-Q-Q, Q-Q-LIT, Q-TOF, TOF-TOF, and LTQ-FTICR. Their analytical characteristics and capabilities are summarized in Table 1. Many reviews of MS instrumentation have been previously published $[3,4]$. In this review we summarize the most significant advances over the past two years in MS technology for proteomics.

\section{LTQ-Orbitrap}

A new type of mass analyzer, the Orbitrap, was invented by Makarov in 1999 [5] and was reported as a tool for proteomics research in 2005 by Hu et al [6]. In the Orbitrap, ions are trapped and orbit around a central spindle-like electrode and oscillate harmonically along its axis with a frequency characteristic of their $\mathrm{m} / \mathrm{z}$ values, inducing an image current in the outer electrodes that is Fourier transformed into the time domain producing mass spectra. On the basis of this development, a new hybrid mass spectrometer became commercial available very recently (LTQ-Orbitrap, Thermo Fisher Scientific) [7]. It consists of a LTQ coupled to a Ctrap and the Orbitrap. It combines the robustness, sensitivity and MS/MS capability of the LTQ with very high mass accuracy and high-resolution capabilities of the Orbitrap, and has become a powerful tool in proteomics. Yates et al. reported using the LTQ-Orbitrap for peptide analysis of a digested human saliva sample in a shotgun bottom-up fashion [8]. The instrument is capable of mass resolution in excess of 40000 and mass measurement accuracies of less than $2 \mathrm{ppm}$ for the analysis of complex peptide mixtures. Macek et al. investigated the utility of the Orbitrap instrument for top-down protein analysis, in which intact protein standards from 10 to $25 \mathrm{kDa}$ were measured in the Orbitrap with absolute mass accuracies between 0.92 and 2.8 ppm using the "lock mass" mode of operation, and the fragment ions produced in the LTQ were accurately measured by the Orbitrap [9]. In a quantitative analysis of stable isotope labeled peptides from complex yeast cell lysate, Venable et al. demonstrated that the high mass accuracy, high resolution, large ion capacity, and large dynamic range of the LTQ-Orbitrap led to as much as 4- to 5-fold improvements in the number and quality of the peptide ratio measurements compared to the LTQ alone [10].

\section{Fragmentation methods}

Tandem mass spectrometry (MS/MS) is a key technique for protein or peptide sequencing and PTM analysis. Collision-induced dissociation (CID) [11] has been the most widely used MS/ 
MS technique in proteomics research. In this method, gas-phase peptide/protein cations are internally heated by multiple collisions with rare gas atoms. This leads to peptide backbone fragmentation of the $\mathrm{C}-\mathrm{N}$ bond resulting in a series of $\mathrm{b}$ - and $\mathrm{y}$-fragment ions. Due to the slowheating, energetic feature associated with this method, internal fragmentation and neutrallosses of $\mathrm{H}_{2} \mathrm{O}, \mathrm{NH}_{3}$, and labile PTMs are common. This also results in limited sequence information for large peptides (>15 amino acids) and intact proteins.

A new fragmentation technique, electron-capture dissociation (ECD) was introduced by the McLafferty laboratory in 1998 [12,13], by which the capture of a thermal electron by a multiply protonated peptide/protein cation induces backbone fragmentation at the $\mathrm{N}-\mathrm{C} \alpha$ bond to produce c- and z-type fragment ions. ECD provides more extensive fragmentation resulting in richer MS/MS spectra and better sequence coverage, and the nonergodic feature of ECD preserves labile PTMs. Therefore it has become a powerful tool for top-down analysis of intact proteins [14-16]. However ECD is most often constrained to the expensive, highly sophisticated FTICR instruments.

An analogous technique, electron-transfer dissociation (ETD) was developed by the Hunt laboratory in 2004 and extends electron capture-like fragmentation to more common bench top mass spectrometers $[17,18]$. In this process, the electrons transfer from radical anions with low electron affinity to multiply protonated peptide cations initiating backbone fragmentation to produce c- and z-ion series. Because the ion-ion reaction is highly efficient and fast, ETD can easily be performed with femtomole quantities of peptides on a chromatographic timescale. ETD MS/MS provides superior sequence coverage for small- to medium-sized peptides and is highly complementary to conventional CID for proteome identification applications [19]. ETD can be utilized to analyze very large peptides as well as intact proteins with a sequential ion/ion reaction, proton transfer/charge reduction (PTR), by which the ETD produced multiply charged fragments are de-protonated with even-electron anions resulting in singly and doubly charged ions that are readily measured by the bench-top low resolution ion trap instrument [20,21]. This allows for sequence analysis of 15-40 amino acids at both $\mathrm{N}$ and C-terminus of the protein. ETD has also shown great promise in labile PTM analyses such as phosphorylation and glycosylation $[22,23]$.

\section{Proteomic strategies for protein identification and PTM characterization}

Protein identification via MS is usually carried out in the form of whole-protein analysis ("topdown" proteomics) or analysis of enzymatically or chemically produced peptides ("bottomup" proteomics). To date various more efficient and effective MS based proteomic strategies have been developed to tackle different biological analytical challenges as shown in Figure 1, among which the separation of peptides and proteins is a key element for both bottom-up and top-down approaches. These separation strategies involve multiple steps such as reverse phase, size-exclusion, isoelectric focusing, ion exchange, etc at the protein level and/or peptide level, conducted off-line or on-line with mass spectrometric analysis, and have been reviewed in several recent publications [24,25].

\section{Shotgun Proteomics}

Bottom-up strategies, in which peptide detection is used to infer protein presence, are the standard for large-scale or high-throughput analysis of highly complex samples. These are usually conducted in two workflows. "Sort-then-break" approaches are performed using offline protein fractionation and separation prior to protein digestion, followed by direct peptide analysis by "peptide mass fingerprinting" (PMF) [26] or further peptide separation by LC interfaced to a tandem mass spectrometer [27]. In "break-then-sort" approaches, protein digestion is performed without any pre-fractionation/separation and peptides are separated by 
multi-dimensional chromatography followed by tandem mass spectrometric analysis, typically using rapidly scanning analyzers such as IT mass spectrometers.

The later approach, commonly referred to as "shotgun proteomics", has gained popularity in the proteomics field [28]. Tandem mass spectra are collected for as many peptides as possible, and the results are then searched by an algorithmic comparison (via SEQUEST [29] or MASCOT [30]) against a database of proteins derived from genomic sequencing to identify the peptides. The resolution and peak capacity of the multi-dimensional separation techniques are critical to the success of the analysis. Among these techniques, multi-dimensional protein identification technology (MudPIT) [31] is now widely implemented and has been applied to analyses of complete cell lysates, organisms, tissue extracts, sub-cellular fractions, and other sub-proteomes [32]. Recent advances in MudPIT include improved peptide separation by ultrahigh-pressure LC [33] and anion-and-cation-mixed-bed ion exchange techniques [34]. Incorporation of the newly developed LTQ-Orbitrap and ETD MS/MS technique with MudPIT analysis should improve peptide accurate mass measurement and peptide fragmentation schemes.

Although the shotgun approach is conceptually simple, it results in greatly increased complexity of the generated peptide mixture, requiring highly sensitive and efficient separation. Information is also lost upon the conversion of intact proteins into a mixture of peptides, which can lead to incorrect identifications. Not all peptides resulting from the digestion of a protein can be observed or correctly identified with MS analysis, especially those with diverse or unexpected modifications. Furthermore the limited dynamic range of mass spectrometric analysis only allows for the peptides present at high relative abundance to be preferentially sampled, while information regarding the proteins represented as low abundance peptides in the complex mixture is commonly not obtained.

\section{Top-down Proteomics}

A newer proteomics strategy known as the top-down approach involves gas-phase ionization of intact proteins and subsequent high-resolution mass measurement of intact protein ions followed by their direct fragmentation inside the mass spectrometer (mainly FTICR) without prior digestion [35]. In theory, this approach places the entire sequence of the protein under examination, and consequently the top-down approach should enable a more complete characterization of protein isoforms and any PTMs than the bottom-up approach. The top-down appraoch provides direct examination of modifications indicated by the mass discrepancy between the measured mass and the DNA sequence predicted value.

A key to the top-down approach is the ability to fragment intact proteins. The development of ECD in the FTICR has greatly improved the dissociation efficiency for small to medium-sized proteins [12-16]. Large proteins (> 50 kDa), however, could not be readily analyzed due to the increasing complexity of the gas-phase protein ion's tertiary structure with many noncovalent interactions. Recently, Han et al. demonstrated that the top-down approach can be used to analyze proteins as large as $229 \mathrm{kDa}$ by "prefolding dissociation" to dissociate $\sim 240$ residues from each terminus [36]. A related "middle-down" strategy using limited digestion to produce larger peptides ( $>5 \mathrm{kDa}$ ) has also been used for very large proteins or specific protein domains of interest [37]. The recent research of the Kelleher and Hunt laboratories has shown that the top-and middle-down approaches have the capability of tackling challenging biological problems such as deciphering the "histone code" [38] which involves characterization of combinatorial acetylations, methylations, phosphorylations [39,40]. The development of new instrumentation and MS/MS techniques has also expanded demonstrations of the top-down approach on instruments such as the TOF [41], ion trap [21], and LTQ-Orbitrap [9]. 
Although the top-down approach is powerful in protein modification analysis, it is primarily performed with direct infusion of a single protein or simple protein mixture (separated offline), therefore the analytical throughput and efficiency for large-scale proteome analysis is still a major challenge. To address these limitations, increasing efforts have been made to improve the front-end separation of complex protein mixtures and automated database searching informatics. Recently top-down proteomics has been shown promise for higherthroughput proteome analysis as demonstrated by Bryan et al. in an on-line top-down proteomics strategy on a chromatographic time scale using LTQ-FTICR [42].

\section{Quantitative proteomics}

Although mass spectrometry is often only used to demonstrate the presence of a protein or PTM within a sample, it can also be used to measure dynamic changes in protein and PTM abundances. Quantification strategies make use of stable isotopes $\left({ }^{2} \mathrm{H},{ }^{13} \mathrm{C},{ }^{15} \mathrm{~N}\right.$, and $\left.{ }^{18} \mathrm{O}\right)$ for sample labeling although label-free methods have also been proposed. The rationale behind stable isotope labeling is to create a mass shift that distinguishes identical peptides from different samples within a single MS analysis.

The introduction of stable isotopes by metabolic labeling occurs during protein synthesis. Samples can be combined pre-lysis, eliminating the introduction of processing errors. Stable isotope incorporation is sequence-independent, and therefore uniform across the proteome. Metabolic labeling was first applied to proteomic analysis by mass spectrometry using ${ }^{15} \mathrm{~N}$ [43]. It has been successfully applied to model organisms from bacteria to worm to rat [44, 45], although the practicality of labeling an entire organism becomes limiting for organisms with long generation times. Additionally, the amount of stable isotope present within each amino acid is dependent on the number of nitrogen atoms it contains, making downstream analysis more complex. The use of stable isotope labeling of amino acids in cell culture (SILAC) has emerged as a popular alternative in which only select amino acids are labeled, typically arginine and lysine [46]. Following cleavage with trypsin, all peptides contain at least one labeled amino acid. SILAC has proven useful in measuring the output of signaling networks and discerning true protein interactions [47-49].

Post-biosynthetic labeling strategies can be applied to any set of samples, including primary cell culture and human, because they are performed post-lysis. However, sample-processing discrepancies can lead to the introduction of error with these methods. Enzymatic labeling is performed using $\mathrm{H}_{2}{ }^{18} \mathrm{O}$ during the peptide bond hydrolysis step of the digestion [50]. Carboxyl oxygen exchange can result in the addition of a second ${ }^{18} \mathrm{O}$, although this reaction is significantly less efficient and enzyme-dependent. Accurately distinguishing the small mass difference produced by enzymatic labeling requires an instrument with high mass accuracy and high mass resolution. Chemical labeling targets reactive groups on the side-chains of amino acids or peptide termini. Consequently, comprehensive stable isotope incorporation is difficult to achieve because labeling is sequence-dependent. Side reactions are also a common problem. Improving on the use of isotope-coded affinity tags (ICAT) [51], isobaric mass tags are all the same mass and it is only upon fragmentation that the different mass tags are observed [52]. The isobaric mass tag consists of an amine-specific reactive group, a balancer group and a reporter mass group. The peptide amino-termini and lysine side-chains are targeted by the amine-specific reactive group. A popular version of isobaric mass tags is the iTRAQ reagent [53], which has recently expanded to incorporate up to eight reporter mass ions. Consequently, the amount of run time required to analyze multiple samples can be reduced. This is of particular relevance to biological experiments in which multiple conditions or multiple time-points are being evaluated such as signaling networks [54].

The above examples of metabolic and post-biosynthetic labeling all provide relative quantification of proteins. One advantage provided by the use of stable isotope-labeled 
synthetic peptides is that absolute measurement of protein abundance can be achieved. This is possible because a defined amount labeled synthetic peptide is added to the sample. Absolute quantification of proteins uses a synthetic stable isotope-labeled peptide at a known concentration [55]. The choice of peptide is based upon previous sampling results. The use of synthetic peptides for protein quantification by MS is typically performed using selective reaction monitoring (SRM) in which the intact peptide mass and specific fragment ions are monitored during the course of the run. This information, along with retention time, increases confidence in peptide assignments. This technique has been used to monitor phosphorylation events associated with cell cycle transitions [56].

\section{Conclusions and outlook}

Thanks to the combination of developments in new instrumentation, fragmentation methods, and analysis strategies, mass spectrometry has become an indispensable proteomics tool for the interrogation of protein expression, protein interaction and protein modification. The incorporation of mass spectrometry into modern day biology has contributed important insights into complex biological processes such as embryonic stem cell biology [57,58], kinase signaling networks $[59,60]$ and disease $[61,62]$. However, complete characterization of the proteome, qualitatively and quantitatively, remains a tremendous challenge. Low abundance proteins test the limits of sensitivity and dynamic range of the currently available methods. The diversity of potential and combinatorial PTMs adds another layer of complexity that is not simple to decipher. Additionally, the impact of single nucleotide polymorphisms (SNPs) on proteome analysis by mass spectrometry has not been fully investigated. Continued improvements in mass spectrometry technology and methodology will be critical. Finally, the biggest challenge for the future of mass spectrometry-based proteomics will be to make use of the information that is being gathered.

\section{Acknowledgements}

Funding from the National Institutes of Health to JYR (P41 RR011823, 2R01 MH067880, U01 DE016267) and the American Cancer Society to AA (PF-07-279-01-CCG).

\section{References}

- of special interest

•• of outstanding interest

1. Fenn JB, Mann M, Meng CK, Wong SF, Whitehouse CM. Electrospray ionization for mass spectrometry of large biomolecules. Science 1989;246:64-71. [PubMed: 2675315]

2. Karas M, Hillenkamp F. Laser desorption ionization of proteins with molecular masses exceeding 10 000 daltons [1]. Analytical Chemistry 1988;60:2299-2301. [PubMed: 3239801]

3. Yates Iii JR. Mass spectral analysis in proteomics. Annual Review of Biophysics and Biomolecular Structure 2004;33:297-316.

4. Domon B, Aebersold R. Mass spectrometry and protein analysis. Science 2006;312:212-217. [PubMed: 16614208]

5. Makarov A. Electrostatic axially harmonic orbital trapping: A high-performance technique of mass analysis. Analytical Chemistry 2000;72:1156-1162. [PubMed: 10740853]

6. Hu Q, Noll RJ, Li H, Makarov A, Hardman M, Cooks RG. The Orbitrap: A new mass spectrometer. Journal of Mass Spectrometry 2005;40:430-443. [PubMed: 15838939]

7. Makarov A, Denisov E, Kholomeev A, Balschun W, Lange O, Strupat K, Horning S. Performance evaluation of a hybrid linear ion trap/orbitrap mass spectrometer. Analytical Chemistry 2006;78:21132120. [PubMed: 16579588] 
8. Yates JR, Cociorva D, Liao L, Zabrouskov V. Performance of a linear ion trap-orbitrap hybrid for peptide analysis. Analytical Chemistry 2006;78:493-500. [PubMed: 16408932]• This paper reported the first use of LTQ-Orbitrap for shotgun analysis of complex peptide mixture and evaluated the features of this new instrument for bottom-up proteomics.

9. Macek B, Waanders LF, Olsen JV, Mann M. Top-down protein sequencing and MS3 on a hybrid linear quadrupole ion trap-orbitrap mass spectrometer. Molecular and Cellular Proteomics 2006;5:949-958. [PubMed: 16478717]

10. Venable JD, Wohlschlegel J, McClatchy DB, Sung KP, Yates Iii JR. Relative quantification of stable isotope labeled peptides using a linear ion trap-orbitrap hybrid mass spectrometer. Analytical Chemistry 2007;79:3056-3064. [PubMed: 17367114]

11. Shukla AK, Futrell JH. Tandem mass spectrometry: Dissociation of ions by collisional activation. Journal of Mass Spectrometry 2000;35:1069-1090. [PubMed: 11006601]

12. Zubarev RA, Kelleher NL, McLafferty FW. Electron capture dissociation of multiply charged protein cations. A nonergodic process. J. Am. Chem. Soc 1998;120:3265-3266.

13. Zubarev R. Protein primary structure using orthogonal fragmentation techniques in Fourier transform mass spectrometry. Expert Review of Proteomics 2006;3:251-261. [PubMed: 16608437]• A comprehensive review on ECD and its utility in proteomics research.

14. Shi SDH, Hemling ME, Carr SA, Horn DM, Lindh I, McLafferty FW. Phosphopeptide/ phosphoprotein mapping by electron capture dissociation mass spectrometry. Analytical Chemistry 2001;73:19-22. [PubMed: 11195502]

15. Ge Y, Lawhorn BG, ElNaggar M, Strauss E, Park JH, Begley TP, McLafferty FW. Top down characterization of larger proteins $(45 \mathrm{kDa})$ by electron capture dissociation mass spectrometry. Journal of the American Chemical Society 2002;124:672-678. [PubMed: 11804498]

16. Zabrouskov V, Whitelegge JP. Increased coverage in the transmembrane domain with activated-ion electron capture dissociation for top-down fourier-transform mass spectrometry of integral membrane proteins. Journal of Proteome Research 2007;6:2205-2210. [PubMed: 17441748]

17. Syka JEP, Coon JJ, Schroeder MJ, Shabanowitz J, Hunt DF. Peptide and protein sequence analysis by electron transfer dissociation mass spectrometry. Proceedings of the National Academy of Sciences of the United States of America 2004;101:9528-9533. [PubMed: 15210983]

18. Pitteri SJ, Chrisman PA, Hogan JM, McLuckey SA. Electron transfer ion/ion reactions in a threedimensional quadrupole ion trap: Reactions of doubly and triply protonated peptides with SO 2 ? Analytical Chemistry 2005;77:1831-1839. [PubMed: 15762593]

19. Good DM, Wirtala M, McAlister GC, Coon JJ. Performance characteristics of electron transfer dissociation mass spectrometry. Molecular and Cellular Proteomics 2007;6:1942-1951. [PubMed: 17673454]• This paper reports the largest scale study of ETD to date using commercial ETD-capable MS system and demonstrates that ETD is a highly complementary approach to CID for peptide sequence analysis. The instrument parameters for ETD experiment were also investisgated.

20. Coon JJ, Ueberheide B, Syka JEP, Dryhurst DD, Ausio J, Shabanowitz J, Hunt DF. Protein identification using sequential ion/ion reactions and tandem mass spectrometry. Proceedings of the National Academy of Sciences of the United States of America 2005;102:9463-9468. [PubMed: 15983376]

21. Chi A, Bai DL, Geer LY, Shabanowitz J, Hunt DF. Analysis of intact proteins on a chromatographic time scale by electron transfer dissociation tandem mass spectrometry. International Journal of Mass Spectrometry 2007;259:197-203. [PubMed: 17364019]

22. Chi A, Huttenhower C, Geer LY, Coon JJ, Syka JEP, Bai DL, Shabanowitz J, Burke DJ, Troyanskaya OG, Hunt DF. Analysis of phosphorylation sites on proteins from Saccharomyces cerevisiae by electron transfer dissociation (ETD) mass spectrometry. Proceedings of the National Academy of Sciences of the United States of America 2007;104:2193-2198. [PubMed: 17287358]

23. Udeshi ND, Shabanowitz J, Hunt DF, Rose KL. Analysis of proteins and peptides on a chromatographic timescale by electron-transfer dissociation MS. FEBS Journal 2007;274:62696276. [PubMed: 18021239]•• An overview of ETD technology and its application for protein/peptide identification and PTM characterization on a chromatographic timescale. 
24. Issaq HJ, Chan KC, Janini GM, Conrads TP, Veenstra TD. Multidimensional separation of peptides for effective proteomic analysis. Journal of Chromatography B: Analytical Technologies in the Biomedical and Life Sciences 2005;817:35-47.

25. Fournier ML, Gilmore JM, Martin-Brown SA, Washburn MP. Multidimensional separations-based shotgun proteomics. Chemical Reviews 2007;107:3654-3686. [PubMed: 17649983]•• A comprehensive review on the development of multidimensional chromatography coupled to tandem mass spectrometry for shotgun proteomics analysis.

26. Henzel WJ, Billeci TM, Stults JT, Wong SC, Grimley C, Watanabe C. Identifying proteins from twodimensional gels by molecular mass searching of peptide fragments in protein sequence databases. Proceedings of the National Academy of Sciences of the United States of America 1993;90:50115015. [PubMed: 8506346]

27. Ogorzalek Loo RR, Hayes R, Yang Y, Hung F, Ramachandran P, Kim N, Gunsalus R, Loo JA. Topdown, bottom-up, and side-to-side proteomics with virtual 2-D gels. International Journal of Mass Spectrometry 2005;240:317-325.

28. McDonald WH, Yates Iii JR. Shotgun proteomics: Integrating technologies to answer biological questions. Current Opinion in Molecular Therapeutics 2003;5:302-309. [PubMed: 12870441]

29. Eng JK, McCormack AL, Yates JR. An approach to correlate tandem mass spectral data of peptides with amino acid sequences in a protein database. J. Am. Soc. Mass Spectrom 1994;5:976-989.

30. Perkins DN, Pappin DJC, Creasy DM, Cottrell JS. Probability-based protein identification by searching sequence databases using mass spectrometry data. Electrophoresis 1999;20:3551-3567. [PubMed: 10612281]

31. Washburn MP, Wolters D, Yates JR. Large-scale analysis of the yeast proteome by multidimensional protein identification technology. Nature Biotechnology 2001;19:242-247.

32. Delahunty CM, Yates Iii JR. MudPIT: Multidimensional protein identification technology. BioTechniques 2007;43:563-569. [PubMed: 18072585]

33. Livesay EA, Tang K, Taylor BK, Buschbach MA, Hopkins DF, LaMarche BL, Zhao R, Shen Y, Orton DJ, Moore RJ, et al. Fully automated four-column capillary LC-MS system for maximizing throughput in proteomic analyses. Analytical Chemistry 2008;80:294-302. [PubMed: 18044960]

34. Motoyama A, Xu T, Ruse CI, Wohlschlegel JA, Yates Iii JR. Anion and cation mixed-bed ion exchange for enhanced multidimensional separations of peptides and phosphopeptides. Analytical Chemistry 2007;79:3623-3634. [PubMed: 17411013]

35. McLafferty FW, Breuker K, Jin M, Han X, Infusini G, Jiang H, Kong X, Begley TP. Top-down MS, a powerful complement to the high capabilities of proteolysis proteomics. FEBS Journal 2007;274:6256-6268. [PubMed: 18021240]

36. Han X, Jin M, Breuker K, McLafferty FW. Extending top-down mass spectrometry to proteins with masses great than 200 kilodaltons. Science 2006;314:109-112. [PubMed: 17023655]•• This report described utility of "prefolding dissociation" for top-down analysis of several large proteins and successfully extended the top-down mass spectrometry to proteins as large as $229 \mathrm{kDa}$.

37. Garcia BA, Siuti N, Thomas CE, Mizzen CA, Kelleher NL. Characterization of neurohistone variants and post-translational modifications by electron capture dissociation mass spectrometry. International Journal of Mass Spectrometry 2007;259:184-196.

38. Jenuwein T, Allis CD. Translating the histone code. Science 2001;293:1074-1080. [PubMed: 11498575]

39. Siuti N, Kelleher NL. Decoding protein modifications using top-down mass spectrometry. Nature Methods 2007;4:817-821. [PubMed: 17901871]•• An overview of top-down mass spectrometry and its applications in proteomics research of histone code, protein-level variation, and membrane proteins.

40. Garcia BA, Shabanowitz J, Hunt DF. Characterization of histones and their post-translational modifications by mass spectrometry. Current Opinion in Chemical Biology 2007;11:66-73. [PubMed: 17157550]

41. Ogorzalek Loo RR, Cavalcoli JD, VanBogelen RA, Mitchell C, Loo JA, Moldover B, Andrews PC. Virtual 2-D gel electrophoresis: Visualization and analysis of the E. coli proteome by mass spectrometry. Analytical Chemistry 2001;73:4063-4070. [PubMed: 11569793] 
42. Parks BA, Jiang L, Thomas PM, Wenger CD, Roth MJ, Boyne Ii MT, Burke PV, Kwast KE, Kelleher NL. Top-down proteomics on a chromatographic time scale using linear ion trap Fourier transform hybrid mass spectrometers. Analytical Chemistry 2007;79:7984-7991. [PubMed: 17915963]• This paper presented the first demonstration of large scale top-down proteomics on LTQ-FTICR systems using high-resolution MS/MS data obtained on a chromatographic timescale.

43. Oda Y, Huang K, Cross FR, Cowburn D, Chait BT. Accurate quantitation of protein expression and site-specific phosphorylation. Proceedings of the National Academy of Sciences of the United States of America 1999;96:6591-6596. [PubMed: 10359756]

44. Dong MQ, Venable JD, Au N, Xu T, Sung KP, Cociorva D, Johnson JR, Dillin A, Yates Iii JR. Quantitative mass spectrometry identifies insulin signaling targets in C. elegans. Science 2007;317:660-663. [PubMed: 17673661]• This report used metobolic labeling with ${ }^{15} \mathrm{~N}$ to identify proteins involved in the insulin signaling pathway using the nematode C. elegans.

45. McClatchy DB, Dong MQ, Wu CC, Venable JD, Yates JR 3rd. 15N metabolic labeling of mammalian tissue with slow protein turnover. J Proteome Res 2007;6:2005-2010. [PubMed: 17375949]

46. Ong SE, Blagoev B, Kratchmarova I, Kristensen DB, Steen H, Pandey A, Mann M. Stable isotope labeling by amino acids in cell culture, SILAC, as a simple and accurate approach to expression proteomics. Mol Cell Proteomics 2002;1:376-386. [PubMed: 12118079]

47. Vermeulen M, Mulder KW, Denissov S, Pijnappel WW, van Schaik FM, Varier RA, Baltissen MP, Stunnenberg HG, Mann M, Timmers HT. Selective anchoring of TFIID to nucleosomes by trimethylation of histone H3 lysine 4. Cell 2007;131:58-69. [PubMed: 17884155]•• This report used SILAC to distinguish $\mathrm{H} 3 \mathrm{~K} 4 \mathrm{me} 3$ binding proteins from background non-specific interactions, leading to the identification of TFIID and a novel connection between the regulation of transcription and histone modification.

48. Guo A, Villen J, Kornhauser J, Lee KA, Stokes MP, Rikova K, Possemato A, Nardone J, Innocenti G, Wetzel R, et al. Signaling networks assembled by oncogenic EGFR and c-Met. Proc Natl Acad Sci U S A 2008;105:692-697. [PubMed: 18180459]• This report used SILAC to investigate EGFR and c-met phospho-tyrosine signaling in non-small cell lung cancer cell lines and identified signaling networks associated with sensitivity to specific drug treatments.

49. Kruger M, Kratchmarova I, Blagoev B, Tseng YH, Kahn CR, Mann M. Dissection of the insulin signaling pathway via quantitative phosphoproteomics. Proc Natl Acad Sci U S A 2008;105:24512456. [PubMed: 18268350]

50. Schnolzer M, Jedrzejewski P, Lehmann WD. Protease-catalyzed incorporation of 180 into peptide fragments and its application for protein sequencing by electrospray and matrix-assisted laser desorption/ionization mass spectrometry. Electrophoresis 1996;17:945-953. [PubMed: 8783021]

51. Gygi SP, Rist B, Gerber SA, Turecek F, Gelb MH, Aebersold R. Quantitative analysis of complex protein mixtures using isotope-coded affinity tags. Nature Biotechnology 1999;17:994-999.

52. Thompson A, Schafer J, Kuhn K, Kienle S, Schwarz J, Schmidt G, Neumann T, Johnstone R, Mohammed AK, Hamon C. Tandem mass tags: a novel quantification strategy for comparative analysis of complex protein mixtures by MS/MS. Anal Chem 2003;75:1895-1904. [PubMed: 12713048]

53. Ross PL, Huang YN, Marchese JN, Williamson B, Parker K, Hattan S, Khainovski N, Pillai S, Dey $\mathrm{S}$, Daniels S, et al. Multiplexed protein quantitation in Saccharomyces cerevisiae using aminereactive isobaric tagging reagents. Mol Cell Proteomics 2004;3:1154-1169. [PubMed: 15385600]

54. Wolf-Yadlin A, Hautaniemi S, Lauffenburger DA, White FM. Multiple reaction monitoring for robust quantitative proteomic analysis of cellular signaling networks. Proc Natl Acad Sci U S A 2007;104:5860-5865. [PubMed: 17389395]•• This report used iTRAQ and multiple reaction monitoring to follow tyrosine phosphorylation events downstream of EGF stimulation over time. It improved the reproducibility of identification/quantification across multiple samples.

55. Gerber SA, Rush J, Stemman O, Kirschner MW, Gygi SP. Absolute quantification of proteins and phosphoproteins from cell lysates by tandem MS. Proc Natl Acad Sci U S A 2003;100:6940-6945. [PubMed: 12771378]

56. Mayya V, Rezual K, Wu L, Fong MB, Han DK. Absolute quantification of multisite phosphorylation by selective reaction monitoring mass spectrometry: determination of inhibitory phosphorylation status of cyclin-dependent kinases. Mol Cell Proteomics 2006;5:1146-1157. [PubMed: 16546994] 
57. Phanstiel D, Brumbaugh J, Berggren WT, Conard K, Feng X, Levenstein ME, McAlister GC, Thomson JA, Coon JJ. Mass spectrometry identifies and quantifies 74 unique histone H4 isoforms in differentiating human embryonic stem cells. Proceedings of the National Academy of Sciences of the United States of America 2008;105:4093-4098. [PubMed: 18326628]

58. Wang J, Rao S, Chu J, Shen X, Levasseur DN, Theunissen TW, Orkin SH. A protein interaction network for pluripotency of embryonic stem cells. Nature 2006;444:364-368. [PubMed: 17093407]

59. Matsuoka S, Ballif BA, Smogorzewska A, McDonald Iii ER, Hurov KE, Luo J, Bakalarski CE, Zhao Z, Solimini N, Lerenthal Y, et al. ATM and ATR substrate analysis reveals extensive protein networks responsive to DNA damage. Science 2007;316:1160-1166. [PubMed: 17525332]

60. Stokes MP, Rush J, MacNeill J, Jian MR, Sprott K, Nardone J, Yang V, Beausoleil SA, Gygi SP, Livingstone M, et al. Profiling of UV-induced ATM/ATR signaling pathways. Proceedings of the National Academy of Sciences of the United States of America 2007;104:19855-19860. [PubMed: 18077418]

61. Wang X, Venable J, LaPointe P, Hutt DM, Koulov AV, Coppinger J, Gurkan C, Kellner W, Matteson J, Plutner H, et al. Hsp90 Cochaperone Aha1 Downregulation Rescues Misfolding of CFTR in Cystic Fibrosis. Cell 2006;127:803-815. [PubMed: 17110338]

62. Elenitoba-Johnson KSJ, Crockett DK, Schumacher JA, Jenson SD, Coffin CM, Rockwood AL, Lim MS. Proteomic identification of oncogenic chromosomal translocation partners encoding chimeric anaplastic lymphoma kinase fusion proteins. Proceedings of the National Academy of Sciences of the United States of America 2006;103:7402-7407. [PubMed: 16651537] 


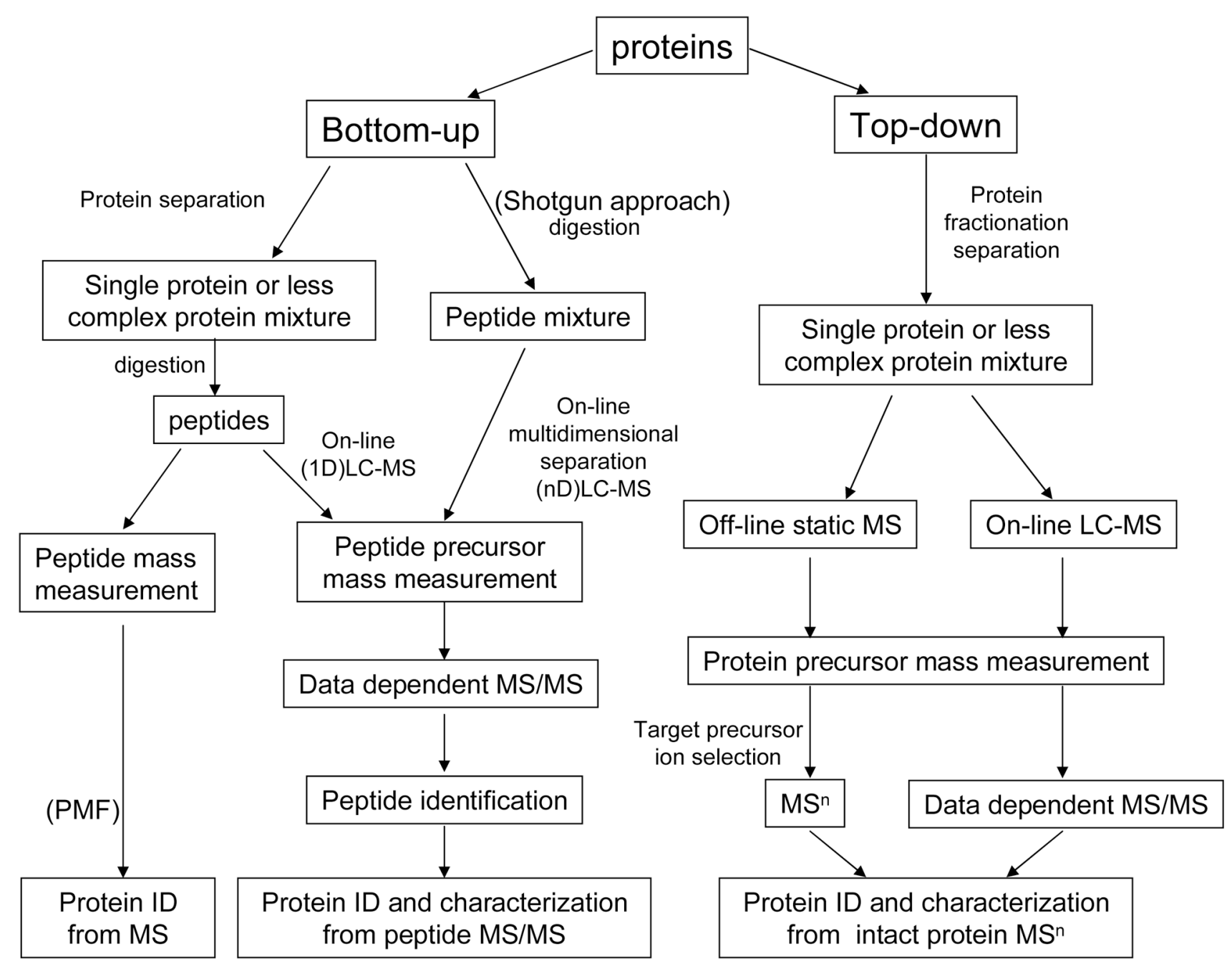

Figure 1.

Strategies for MS-based protein identification and characterization. Proteins extracted from biological samples can be analyzed by bottom-up or top-down methods. In the bottom-up approach, proteins in complex mixtures can be separated prior to enzymatic (or chemical) digestion followed by direct peptide mass fingerprinting-based acquisition or further peptide separation on-line coupled to tandem mass spectrometry. Alternatively, the protein mixture can be directly digested into a collection of peptides ("shotgun" approach), which are then separated by multidimensional chromatography on-line coupled to tandem mass spectrometric analysis. In the top-down approach, proteins in complex mixtures are fractionated and separated into pure single proteins or less complex protein mixtures, followed by off-line static infusion of sample into the mass spectrometer for intact protein mass measurement and intact protein fragmentation. An on-line LC-MS strategy can also be used for large scale protein interrogation. 


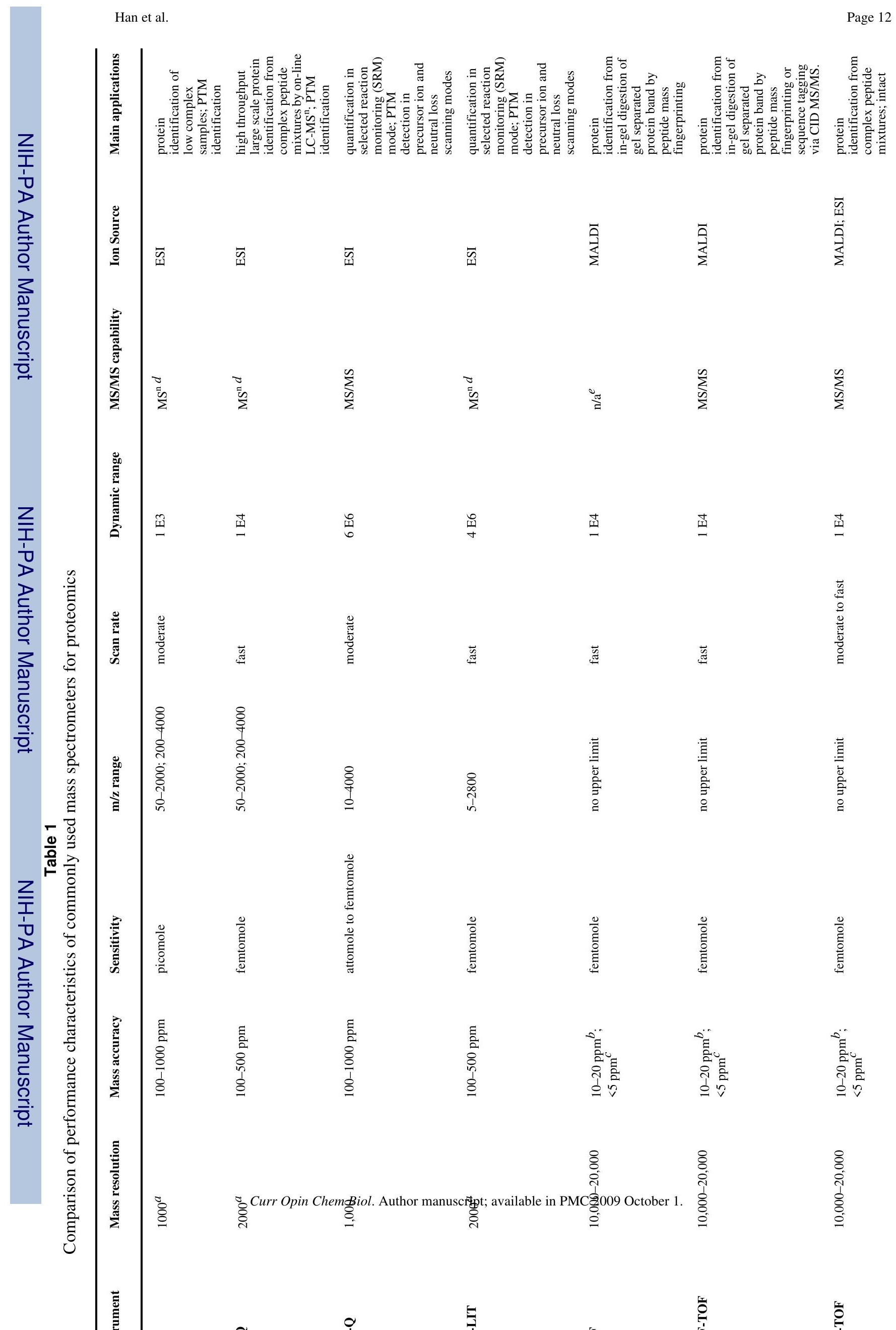


Han et al.

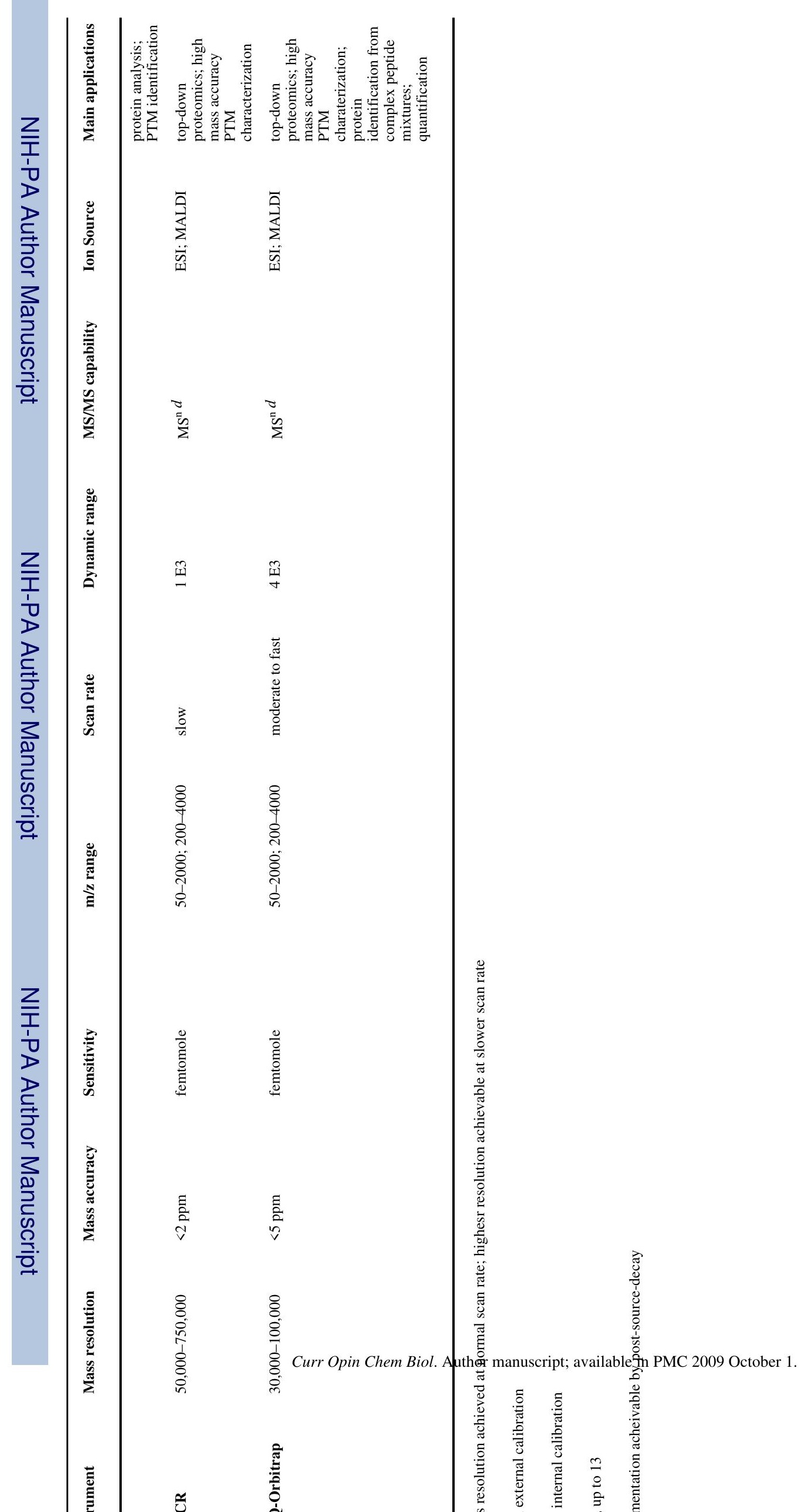

